\title{
A note on possession and mereology in Ulwa property concept constructions
}

\author{
Itamar Francez ${ }^{1}$ - Andrew Koontz-Garboden ${ }^{2}$
}

Received: 14 October 2013 / Accepted: 24 June 2014 / Published online: 28 July 2015

(C) The Author(s) 2015. This article is published with open access at Springerlink.com

\begin{abstract}
Ulwa (Misumalpan; Nicaragua) shows a puzzling and unique pattern in which a single affix marks the head of a possessive noun phrase and appears on roots expressing property concepts. This pattern has been argued to be semantically motivated by Koontz-Garboden and Francez (2010). This paper discusses two constructions of Ulwa that do not receive a natural treatment in their analysis, potentially casting doubt on the plausibility of a semantic motivation for the syncretism. We provide a modified version of the analysis, in which property concept roots denote mereologically ordered sets of portions of substance (in the spirit of Link's 2002 treatment of mass nouns), as argued for in Francez and Koontz-Garboden (2015), rather than property theoretic ones. Possessive relations are then taken to include mereological ones. Such an analysis not only retains the motivation for a semantic approach to the syncretism, but also strengthens it, by showing that the range of interpretations available to the allegedly possessive affix is one expected of possessive lexemes more generally.
\end{abstract}

Keywords Possession - Ulwa · Gradability · Property concepts · Mereology $\cdot$ Mass nouns

\section{Introduction}

The Misumalpan language Ulwa (Nicaragua) shows a puzzling pattern of syncretism in which an affix, $-k a$, occurs both on the head noun in a possessive noun phrase and

\footnotetext{
$\triangle$ A. Koontz-Garboden

andrewkg@manchester.ac.uk

I. Francez

ifrancez@uchicago.edu

1 University of Chicago, Chicago, IL, USA

2 University of Manchester, Manchester, UK
} 
on roots naming property concepts (concepts expressed by adjectives in languages with that category, Dixon 1982). In both cases, the resulting form is a noun. To our knowledge, the particular array of facts is unique to the Misumalpan languages. This pattern, shown in (1), is described and analyzed by Koontz-Garboden and Francez (Koontz-Garboden and Francez 2010; Francez and Koontz-Garboden 2015; KoontzGarboden 2015, to appear). ${ }^{1}$
a. yang as-ki-na minisih-ka.
1SING shirt-<1 SING.POSS > dirtiness-3SING.POSS
'My shirt is dirty.'
b. Alberto pan-ka
Alberto stick-3SING
'Alberto's stick.'

(Green 2004, asna)

When a form (in this case, morpheme) that occurs in one grammatical environment (in this case, head of a possessive noun phrase) surfaces in another, seemingly unrelated environment (here, the formation of a property concept predicate), the question arises whether that is a case of accidental homophony specific to the language, or whether the distribution of the form is motivated by grammatical considerations. If the latter, an analysis must determine and express the relevant grammatical considerations. Koontz-Garboden and Francez (2010) show, based on evidence from the Misumalpan language family, that the data in (1) do not involve accidental homophony. Koontz-Garboden and Francez then develop an argument linking the pattern to a more general crosslinguistic phenomenon they call possessive strategies of predication. These are grammatical strategies in which morphosyntactic material used for the expression of possession functions in the expression of the translational equivalents of predicative constructions with adjectives in languages like English. Koontz-Garboden and Francez argue that the use of possession in predicative contexts is semantically motivated, and construct a semantic account of the Ulwa facts to support this argument. On their analysis, property concept roots ${ }^{2}$ denote properties (in the sense

\footnotetext{
${ }^{1}$ Ulwa data below come from Green's (2004) electronic dictionary (generously made available to us by Tom Green), a corpus of Ulwa texts, or original field notes based on fieldwork carried out between 20042011. Each example is labelled as to its source.

Glossing conventions throughout the paper are as follows: APPL, applicative; AUX, auxiliary; COP, copula; -DA-, $-d a-$ verb class marker (see Koontz-Garboden 2009b for description and analysis of Ulwa verb class morphology); DEF, definite article; DS, different subject switch reference marking; NEG, negative; NON-NOM, non-nominative case; PA, $-p a-$ verb class marker; PAST, past tense; PL.EXCL, plural exclusive (of first person plural); PL.INCL, plural inclusive (of first person plural); PL, plural; PRES, present tense; RAUPI, the Ulwa marker raupi (see Koontz-Garboden 2009b, 476ff.), very roughly a marker of subjecthood; SENT.KA, the sentential $k a$ marker in Ulwa (on which see Koontz-Garboden 2009a); SING, singular; SS, same subject switch reference marking; TA, $-t a$ - verb class marker; TOP, topic marker; WA, $-w a-$ verb class marker; 1,2,3, 1st, 2nd, 3rd person agreement; $<>$, gloss inside angle brackets indicates glossed morpheme is an infix.

${ }^{2}$ The Ulwa items expressing property concepts are roots in the traditional morphological sense, i.e. precategorial items which cannot stand alone as syntactic words without further derivation. The morphosyntactic role of $-k a$, as discussed by Koontz-Garboden (2007, Chap. 6), is to create free-standing words from these morphologically bound roots. Koontz-Garboden (2007, 162-169) provides a series of arguments that these derived words are nominal in their syntactic category, not adjectival. See discussion in Koontz-Garboden (2007) for the lack of convincing evidence in favor of the existence of adjectives in Ulwa, and similar discussion in Green (1992) for the related Miskitu.
} 
of property theory; Chierchia and Turner 1988), and $-k a$ is a possessive morpheme whose semantic role is to relate properties to their bearers.

However, there are two puzzling constructions of Ulwa to which their analysis does not extend naturally, and the correct truth conditions of which they fail to capture. The first, illustrated by the data in (2), has property concept nouns in $-k a$ occurring in the complement of the possessive verb watah. As (3) shows, the same position can host a bare root. The occurrence of a bare root in this environment is unsurprising on Koontz-Garboden and Francez' theory, since watah is a possessive verb and so, for them, makes the same semantic contribution as $-k a$. The occurrence of a derived property concept noun, however, is more surprising, since the presence of the possessive verb watah renders $-k a$ semantically redundant (or vice versa).

Jessica bas-ka ya tubak-ka watah $k a$.

Jessica hair-3SING the thick-KA have SENT-KA

'Jessica's hair is thick.'

(Simplified from Oct09-134)

Yâka û-ka yâka yûh-ka. An tarat watah ka.

that house-3SING that long-KA. and tall have SENT-KA

'That house is long. And it's tall.'

(Oct09-109)

As discussed by Koontz-Garboden and Francez (2010, 235), versions with and without $-k a$ seem to be in free variation in this position, with no clear difference in meaning. The question is how this could be the case. The second mysterious construction is one in which property concept nouns in $-k a$ occur as heads of possessive noun phrases, as shown in (4).

Bilam sikamh-ka-ka $\quad$ raupi $y$ - $\hat{a}$-tak
fish stench-3SING-3SING RAUPI 1 SING.NON-NOM-cause-3SING.DS
kang lâ-wa-yang
APPL cross-WA-1SING.PRES Bob DEF fish have SENT-KA

'The stench of the fish makes me aware that Bob has fish.'

(Mar06-56)

Koontz-Garboden and Francez (2010) discuss both sets of facts, but as we argue below, their analysis of them is unsatisfactory, failing to assign to them the most salient interpretations they have. This failure poses a threat to their broader claim that the distribution of $-k a$ is grammatically, and specifically semantically, motivated.

The goal of this short paper is to show that the semantic explanation of the Ulwa pattern can be maintained, and the relevant constructions accommodated, on a more nuanced approach to the semantics of Ulwa property concept roots, and to the nature of possession. Specifically, in a paper dealing with possessive strategies of predication more generally, Francez and Koontz-Garboden (2015) argue that the semantics of gradability and comparison requires modeling properties not as simple individuals, but as entities they call substances and model using the algebraic mereological approach to mass terms in Link (2002). We propose a modified analysis of the problematic Ulwa facts, building on this alternative view of properties as substances. The analysis takes as its point of departure the fact that in ordinary Ulwa possessive noun phrases, the possessive relation contributed by $-k a$ can be a mereological part-whole 
relation. We show that taking $-k a$ to express the mereological relation ordering substances when it combines with property concept roots leads to a correct analysis of both problematic constructions. Under this revised analysis, the view of the Ulwa pattern as semantically motivated is not only maintained, but strengthened, since the possessive affix $-k a$ emerges as having a range of interpretations that, we show, is natural given what is known about possession in Ulwa and crosslinguistically.

We begin by outlining Koontz-Garboden and Francez' (2010) analysis of Ulwa $-k a$, demonstrating the problems it encounters with the two constructions described above. We then present the alternative analysis and arguments in its favor, and close with some concluding observations.

\section{The property possession analysis of predication}

The main idea of Koontz-Garboden and Francez (2010) is that Ulwa property concept roots denote properties, where properties are simple individuals in the propertytheoretic sense of Chierchia and Turner (1988). Properties are distinguished sortally from "regular" individuals, the former are type $p$, the latter $e$. For example, a root like minisih - in (1) is a referential expression and denotes an individual $\mathbf{d}$ of type $p$, intuitively the property of dirtiness. The morpheme $-k a$ is a possessive morpheme, relating individuals to other individuals by a possessive relation $\pi$. Koontz-Garboden and Francez $(2010,223-224)$ associate two model-theoretic denotations with $-k a .^{3}$ These two denotations are given in (5) (where $\Pi$ is a variable over properties, $P$ over predicates of ordinary individuals, and $x, y$ over individuals).

$$
\begin{aligned}
& \text { a. On PC roots: } \llbracket-\mathrm{ka} \rrbracket=\lambda \Pi \lambda x[\pi(\Pi, x)] \\
& \text { b. On possessed nouns: } \llbracket-\mathrm{ka} \rrbracket=\lambda P \lambda x \lambda y[P(y) \& \pi(x, y) \rrbracket
\end{aligned}
$$

As they point out, associating two denotations with $-k a$ is inevitable given the syntactic environments it occurs in, but the contribution made by the two denotations to the assertion, or truth conditional content, of the resulting sentence is the same in both cases, namely the relation of two individuals by $\pi$. In combination with a root, $-k a$ yields the predicate that is true of any individual if that individual has the property denoted by the root, so that a property concept noun like minisihka in (1) means, roughly, has dirtiness. Possessive morphology is required, on this analysis, to derive predicates from referential roots.

The two constructions described above in (2) and (4) seem surprising at first in light of this analysis, since they each involve two instances of a possessive element. In (2), the possessive morpheme $-k a$ co-occurs with the possessive verb watah 'have', and in (4), it co-occurs with another instance of $-k a$. If possessive semantics is required to turn root-denotations into predicates, what is the role of the second possessive marker? In the following, we discuss these constructions in more detail, and

\footnotetext{
${ }^{3}$ Here we omit discussion of cases in which the possessor is an indefinite or a quantifier; such cases are discussed in Koontz-Garboden and Francez (2010). See Barker (1995) for more general discussion of quantified possessives within the kind of analysis assumed here, and Peters and Westerståhl (2006), Francez (2009) for alternatives.
} 
show the Koontz-Garboden and Francez (2010) analysis of them, explaining why it is unsatisfactory. We refer to the construction in (2) as the $-k a$ watah construction, and to the one in (4) as the double-ka construction.

\section{1 -ka watah constructions}

The $-k a$ watah construction is exemplified in (2) and by the additional data in (6).

a. Jessicabas-ka ya tubak-ka, salai-ka, yûh-ka palkawatah Jessica hair-3SING the thick-KA smooth-KA long-KA very have $k a$.

SENT-KA

'Jessica's hair is thick, smooth, and very long.'

b. Yang tal-yang yang $\hat{u}$-ki karakUlwa $\hat{u}$-ka ya 1SING see-1SING 1SING house-1SING with Ulwa house-3SING the kanas mau-ka watah ka. more clean-KA have SENT-KA 'Between my house and the Ulwa house (= the house of the Ulwa Language Project), my house is cleaner.'

c. Âka dî-ka basta laih dî̀-ram katka batak-ka this thing-3SING medicine TOP drink-2SING.IRR but bitter-KA watah ka.

have SENT-KA

'This medicine, you'll drink it, but it's bitter.'

(0405-809)

According to Koontz-Garboden and Francez' analysis, $-k a$ and watah have the denotations in (7) ((7-a) repeated from (5-a)), $-k a$ denoting a relation between properties and individuals that possess them and watah denoting a relation between individuals standing in the possessive relation to one another.

$$
\begin{array}{ll}
\text { a. } & \llbracket-\mathrm{ka} \rrbracket=\lambda \Pi \lambda x \cdot \pi(\Pi, x) \\
\text { b. } & \llbracket \text { watah } \rrbracket=\lambda x \lambda y . \pi(x, y)
\end{array}
$$

Glossing over the formal details of the LF-based semantics they assume for possessive descriptions, their analysis assigns to the sentence in (8) (a simplified version of (6-a)), the truth conditions in (9), where thickness is a constant of type $p .^{4}$

Jessica bas-ka ya tubak-ka watah $k a$.

Jessica hair-3SING the thick-KA have SENT-KA

'Jessica's hair is thick.'

(Simplified from Oct09-134)

$(\llbracket$ Jessica bas-ka ya $\rrbracket) \llbracket$ tubak-ka watah $\rrbracket=$

$\exists y[\pi$ (J's hair, $y) \& \pi$ ( $y$, thickness) $]]$

These truth conditions ensure that Jessica's hair has something thick, but not that is has thickness, i.e. not that it $i$ s thick (recall that the analysis equates having thickness

\footnotetext{
${ }^{4}$ For the full details of the analysis in the context of the LF-based analysis of possessive descriptions, see Koontz-Garboden and Francez (2010:235ff).
} 
with being thick). Koontz-Garboden and Francez (2010, 237) conjecture that such examples might be viewed as analogous to English examples like (10-a), which is roughly equivalent to (10-b).

(10) a. Jessica's hair has something strange about it.

b. Jessica's hair is strange.

However, this is not a particularly illuminating analogy, as the relevant English examples are very limited, as shown by the oddity of $(11-a, b) .{ }^{5}$

a. \#Jessica has something tall about her.

b. \#Jessica's hair has something black about it.

Furthermore, the desired equivalence with (10-b) cannot be achieved without a prepositional phrase, as shown in (12).

\#Jessica's hair has something strange.

A better analysis of these constructions would not make them exotic in this way, but rather generate a meaning for them consistent with the ordinary predicational meaning that they seem to have.

\subsection{Double $-k a$ constructions}

As shown in (1-b), the head noun of an Ulwa possessive noun phrase, i.e. the one expressing the possessed, is affixed with $-k a$. Since words resulting from suffixing $-k a$ to an Ulwa property concept root are, categorially, nouns (see fn. 2), they too can head a possessive noun phrase, in which case they are again suffixed with $-k a$. This results in 'double' - $k a$ suffixation, as illustrated in (13).

a. Bilam sikamh-ka-ka raupi

fish stinky-3SING-3SING RAUPI

$y$-â-tak

kang lâ-wa-yang

$\mathrm{Bob}$

1SING.NON-NOM-cause-3SING.DS APPL cross-WA-1SING.PRES Bob

ya bilam watah $\mathrm{ka}$.

DEF fish have SENT-KA

'The stinkiness of the fish makes me aware that Bob has fish.'

(Mar06-56)

b. Pâpangh-ni dasi-ka-ka kau baka-ki ya andih

father-1 INCL.PL strong-3SING-3 SING with child-1SING DEF already

ala- $t$ - $i \quad$ bata-ka yak-t-ikda.

raise-TA-SS youth-3SING extract-TA-1 SING.PAST

'With the strength of god, I have already raised my child into a youth.'

(0405-474)

\footnotetext{
${ }^{5}$ Our immediate intuition is that this English construction is licensed only when the adjective involved is multidimensional (see Sassoon 2013 for recent discussion and references). For example, in (10), Jessica's hair is strange in some respect, and not strange in others. (11-a) is odd because Jessica cannot be tall in any respect other than her height.
} 
That this second occurrence of $-k a$ marks possession on the head of a possessive NP is clear from its morphological characteristics. On the head of a possessive noun phrase, $-k a$ agrees with the possessor in person and number, as shown in (14). Precisely the same is true when the possessed noun is a root suffixed with $-k a$, as in double $-k a$ constructions, as shown by the full paradigm in (15) for the root sang'green, alive' given in Green $(1999,81){ }^{6}$

$\begin{array}{lll}\text { Nominal possessive } & \text { paradigm for burimak 'guava' (Green 1999, 177) } \\ \text { 1singular } & \text { buri-ki-mak } & \text { 'my guava' } \\ \text { 2singular } & \text { buri-ma-mak } & \text { 'your guava' } \\ \text { 3singular } & \text { buri-ka-mak } & \text { 'his/her guava' } \\ \text { 1plural, inclusive } & \text { buri-ni-mak } & \text { 'our (inc) guava' } \\ \text { 1plural, exclusive } & \text { buri-kina-mak } & \text { 'our (exc) guava' } \\ \text { 2plural } & \text { buri-mana-mak } & \text { 'your (pl) guava' } \\ \text { 3plural } & \text { buri-kana-mak } & \text { 'their guava' }\end{array}$

Nominal possessive paradigm for sangka 'life/greenness' (Green 1999, 81)

$\begin{array}{lll}\text { 1 singular } & \text { sang-ki-ka } & \text { 'my life/greenness' } \\ \text { 2singular } & \text { sang-ma-ka } & \text { 'your life/greenness' } \\ \text { 3singular } & \text { sang-ka-ka } & \text { 'his/her life/greenness' } \\ \text { 1plural, inclusive } & \text { sang-ni-ka } & \text { 'our (inc) life/greenness' } \\ \text { 1plural, exclusive } & \text { sang-kina-ka } & \text { 'our (exc) life/greenness' } \\ \text { 2plural } & \text { sang-mana-ka } & \text { 'your (pl) life/greenness' } \\ \text { 3plural } & \text { sang-kana-ka } & \text { 'their life/greenness' }\end{array}$

(14) and (15) exemplify a well-known prosodic condition on the position of $-k a$ in possessive noun phrases (see e.g., McCarthy and Prince 1998), namely that $-k a$ can be infixed to the leftmost iamb of the host rather than suffixed. ${ }^{7}$ For example, sang$k i-k a$ is the first singular possessive form of the word sang-ka.

Given the denotations in (5), Koontz-Garboden and Francez' analysis assigns to a noun phrase such as the one in (13-a) the meaning in (16-c) (simplifying somewhat by assuming that the noun bilam 'fish' denotes an individual):

$$
\begin{array}{ll}
\text { a. } & \llbracket \text { sikamh-ka } \rrbracket=\lambda x[\pi(x, S T E N C H)] \\
\text { b. } & \llbracket \text { sikamh-ka-ka } \rrbracket=(\lambda x[\pi(x, S T E N C H)]) \lambda P \lambda x \lambda y[P(y) \& \pi(x, y)]= \\
& \lambda x \lambda y[\pi(y, S T E N C H) \& \pi(x, y)] \\
\text { c. } & \llbracket \text { bilam sikamh-ka-ka } \rrbracket=(f i s h) \lambda x \lambda y[\pi(y, S T E N C H) \& \pi(x, y)]= \\
& \lambda y[\pi(y, S T E N C H) \& \pi(f i s h, y)]= \\
& \text { 'the set of things that have stench that the fish has' }
\end{array}
$$

Again, this does not correspond to the interpretation that such noun phrases normally have. Intuitively, the noun phrase bilamh sikamhka should receive an interpretation matching its gloss, i.e. it should refer to the fish's stench. Instead, on this analysis, it denotes the set of smelly things the fish has. For example, (13-a) on this analysis says

\footnotetext{
${ }^{6}$ We have simplified the table in (14) from (Green 1999, 81) omitting details irrelevant for the discussion here about phonological variation in the paradigm.

${ }^{7}$ This is seen clearly for nouns, like those above, that have more than two syllables.
} 
that something stinky that the fish has alerts me to the fact that Bob has fish, rather than saying that the fish's stench alerts me of this.

In the next section we argue that the problem lies in Koontz-Garboden and Francez' treatment of properties as individuals. We show that modeling properties as substances instead, as proposed in Francez and Koontz-Garboden (2015), opens up a way to assign the problematic sentences the correct truth conditions by capitalizing on well-known observations about the semantic nature of possessive marking.

\section{The alternative analysis}

Francez and Koontz-Garboden (2015) suggest that Ulwa property concept lexemes denote substances. Substances are conceptualized as masses, and are modelled on a par with the denotations of mass nouns in the algebraic approach of Link (2002). They suggest that the possessive material in Ulwa property concept predication is required in order to turn substance-denoting expressions into regular predicates of individuals. Here we provide only the facts of their analysis relevant for the analysis of the Ulwa pattern and of $-k a$ watah and double-ka constructions. The key assumptions are the following:

- The domain of quantification $\mathcal{D}$ is sorted into:

- A non-empty set $\mathcal{E}$ of ordinary individuals and

- A non-empty set $\mathcal{A}$ of portions.

- Substances are subsets of $\mathcal{A}$. Each substance forms a join semi-lattice under the mereological part-of relation $\preceq$.

- $p, q$ are variables over portions in $\mathcal{A} ; P$ is a variable over substances, i.e. subsets of $\mathcal{A}$; and $x, y$ are variables over entities in $\mathcal{D}$ (which is to say, that they are not specified as to their sort)

Ulwa property concept roots denote substances. For example, the root minisih-in (1) denotes the mereologically ordered set of portions of a substance called, for convenience, dirtiness. The meaning of the root is shown in (17), where dirtiness is the function characterizing (the set of portions of) dirtiness.

$$
\llbracket \operatorname{minisih}-\rrbracket=\lambda p[\operatorname{dirtiness}(p)]
$$

The analysis of the Ulwa pattern in (1) remains in essence the same as in KoontzGarboden and Francez (2010), except that properties are modeled as substances, and predication as substance possession. The suffix $-k a$ denotes a function that takes a substance and returns a function characterizing this set of individuals who bear a possessive relation $\pi$ to some portion of the substance, as shown in (18).

$$
\llbracket-\mathrm{ka} \rrbracket=\lambda P \lambda x . \exists q[P(q) \& \pi(x, q)]
$$

The nouns formed by suffixing $-k a$ to a property concept root thus denote predicates of individuals who have a portion of a certain substance, as shown for minisihka 'dirty' in (19).

$$
\llbracket \text { minisih-ka } \rrbracket=\lambda x . \exists q[\operatorname{dirtiness}(q) \& \pi(x, q)]
$$


The point of departure for a better analysis of $-k a$ watah and double-ka constructions is the observation, made repeatedly in the literature (see inter alia Barker 1995; Jensen and Vikner 1996; Heine 1997; Partee 1997; Vikner and Jensen 2002; Tham 2006 and references therein) that, crosslinguistically, nominal possessive morphology is highly underspecified semantically. In particular, among the relations introduced by English nominal possessive morphology are alienable possession (including ownership) (20-a), and a range of relations of inalienable possession or integral part/whole relations in (21).

(20) The girl's car

(21) integral part/whole relation
a. The girl's nose
b. The book's first chapter
c. The car's wheel
d. The sand's grains

Why it is that possessive morphology functions to introduce these semantic relations, i.e. what makes alienable and inalienable possession or integral parthood a natural class, is a very interesting question which we do not attempt to address here. What is important for our purposes is that, unsurprisingly, the same situation obtains also in Ulwa. (22-a) and (22-b) show that $-k a$ is used to introduce ownership relations and part/whole relations, respectively. Additional part/whole examples are given in (23).

a. pâpangh-ki kuring-ka

father-1SING canoe-3SING

'my father's canoe'

(Green 2004, alhnaka)

b. uhkan mak-ka

hone.palm seed-ka

'the seed of the hone palm'

(Green 2004, babaknaka)

(23) integral part/whole relation
a. $\hat{u} \quad p \hat{a} p-k a$
house door-3SING
'the door of the house'
b. yalau ting-ka
mango.tree branch-3SING
'branch of the (mango) tree'
c. kuma mak-ka balna isau
salt piece-ka plural many
'many pieces of salt'
(0405-1073)
(Green 2004, ahauka yaknaka)

Of particular interest is example (23-c), which clearly demonstrates that among the relations expressible by $-k a$ is the relation between masses and their mereological parts.

Our proposal is simply that the relation $\preceq$, the mereological relation ordering substances (see Francez and Koontz-Garboden 2015, 23ff. for details), is one of the possible specifications of the underspecified possessive relation $\pi$. Portions of a substance thus bear $\preceq$ to other portions of the same substance, and they bear another 
possessive relation, for which we use the symbol $R$, to individuals that bear them. $R$ and $\preceq$ differ from one another at a minimum in the latter being a transitive relation. With this as background, we have the formal tools in place to give a more satisfactory analysis to the two constructions of interest.

\subsection{Reanalyzing $-k a$ watah constructions}

We assume the same denotations for $-k a$ and watah, namely the one given in (18) above. Assuming the possessive relation $\pi$ can be resolved into different more specific relations as discussed above, combining $-k a$ with a property concept root can lead to two different interpretations, tied to the realization of $\pi$ as $R$ or $\preceq$. If $\pi$ is resolved to $R$, the possessive relation that holds between individuals and (portions of) substances they have, the derived noun denotes the set of individuals that have some portion of the substance named by the root. This is the meaning of such nouns in predicative position, as in (1-a), repeated in (24). The derivation is shown in (25).

$$
\begin{aligned}
& \text { Yang as-ki-na minisih-ka. } \\
& \text { 1SING shirt-<1SING.POSS > dirtiness-3SING.POSS } \\
& \text { 'My shirt is dirty.' }
\end{aligned}
$$

(Green 2004, asna)

$$
\begin{array}{ll}
\text { a. } & \llbracket \text { minisih } \rrbracket=\lambda p \cdot \operatorname{dirtiness}(p) \\
\text { b. } & \llbracket \text { minisihka } \rrbracket=\lambda x . \exists q[R(x, q) \& \operatorname{dirtiness}(q)] \\
\text { c. } & \llbracket(24) \rrbracket=\exists q[R(\text { my shirt }, q) \& \operatorname{dirtiness}(q)]
\end{array}
$$

When $\pi$ is resolved to $\preceq$, the resulting noun denotes the set of things that have a portion of the substance denoted by the root as a mereological part. This is what we suggest happens in $-k a$ watah constructions. As an example consider again (6), repeated in (26).

$$
\begin{aligned}
& \text { Jessica bas-ka ya tubak-ka watah } k a \text {. } \\
& \text { Jessica hair-3SING the thick-KA have SENT-KA } \\
& \text { 'Jessica's hair is thick.' }
\end{aligned}
$$

(Simplified from Oct09-134)

Resolving the relation introduced by $-k a$ to $\preceq$ gives the noun $t u b a k$ - $k a$ the meaning in (27).

$$
\llbracket \text { tubak-ka } \rrbracket=\lambda q . \exists p[p \preceq q \& \operatorname{thickness}(p)]
$$

In this case, the semantic effect of $-k a$ affixation is to map the substance contributed by the root to the set of things that have some portion of the substance in question as a $\preceq$-part. However, this set is simply the substance itself, since, by the definition of $\preceq$ as a relation that orders substances, all and only portions of a substance have portions of that substance as $\preceq$-parts. This is stated in (28), using $S$ as a metavariable for substances and $s, s^{\prime}$ as metavariables for portions.

$$
\text { For any substance } S:\left\{s: \exists s^{\prime}\left[s^{\prime} \in S \& s^{\prime} \preceq s\right]\right\}=\{s: s \in S\}=S
$$

Resolving $\pi$ to $\preceq$ thus leads to an interpretation for the derived noun which is identical to that of the root, namely the substance named by the root. The full derivation of (26) is given in (29). 


$$
\begin{aligned}
& \text { a. } \llbracket \text { watah } \rrbracket=\lambda P \lambda x . \exists p[R(x, p) \& P(p)]
\end{aligned}
$$

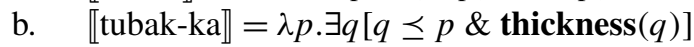

$$
\begin{aligned}
& \text { c. } \llbracket \text { tubak-ka watah } \rrbracket=\llbracket \text { watah } \rrbracket(\llbracket \text { tubak-ka } \rrbracket)= \\
& \lambda x . \exists p[R(x, p) \& \exists q[q \preceq p \& \text { thickness }(q)]] \\
& \text { d. } \quad \llbracket(26) \rrbracket=\exists p[R(\text { Jessica's hair, } p) \& \exists q[q \preceq p \& \text { thickness }(q)]]
\end{aligned}
$$

(29-d) says that Jessica's hair bears the $R$ relation to something which bears the $\preceq$ relation to a portion of thickness. Because anything that bears $\preceq$ to a portion of thickness is itself a portion of thickness, what Jessica's hair bears $R$ to is a portion of thickness. On this interpretation, then, (26) simply says that Jessica's hair has a portion of thickness, i.e. that it is thick. More generally, constructions in which the complement of watah is a root receive exactly the same interpretation as $-k a$ watah constructions, in which that complement is a noun derived from a root by $-k a$ suffixation. ${ }^{8}$ This not only yields the desired truth conditions, but nicely derives the observation that there is genuinely free variation between roots (e.g., tubak) and -ka suffixed property concept nouns (e.g., tubak-ka) in the complement of watah 'have', a fact illustrated above by the data in (2) and (3). Furthermore, while the forms are in free variation in contexts in which they can both occur syntactically, they are not generally in free variation. For example, the double $-k a$ construction discussed below features possessive noun phrases in which the possessed noun denotes a substance. Since roots are not nouns and cannot head possessive noun phrases in Ulwa, they are barred in this construction.

There is, however, a wrinkle in this proposal. Barring some general constraint on the resolution of $\pi$, our analysis also generates the strange meaning generated by Koontz-Garboden and Francez (2010), according to which (26) says that Jessica's hair has something thick (see Sect. 2.1). Since $-k a$ can generally contribute either $\preceq$ or $R$, nothing in our analysis blocks an interpretation in which it contributes $R$ in $-k a$ watah constructions, yielding the undesired reading. This might seem to be a flaw, as the motivation for the current analysis has been to generate the more intuitive meaning for the construction. However, whether or not this is indeed a flaw depends on whether this reading is, in fact, a possible reading of $-k a$ watah sentences. The motivation for reanalyzing them is that it is certainly not their most salient reading. Koontz-Garboden and Francez generate only this reading, and not the salient one. Our analysis generates both. Unfortunately, due to the nature of the strange meaning, the question of its existence is exceedingly difficult to resolve through fieldwork. A context in which this reading would be salient is practically impossible to construct, and requires a kind of metalinguistic judgment that linguistically naive speakers of any language are reluctant to give. But, it is important to keep in mind, to the extent that this reading is in fact impossible, that generally speaking, possessive constructions which do not allow the full range of possible resolutions of the possessive relation $\pi$

\footnotetext{
${ }^{8} \mathrm{~A}$ reviewer points out that, given the semantic equivalence between suffixed roots and unsuffixed roots on this interpretation, there is no semantic obstacle to stacking multiple instances of $-k a$ recursively $a d$ infinitum. The reviewer then raises the question whether such stacking is attested, and if not, why not. In fact, such stacking does not occur in Ulwa, for completely mundane distributional reasons. Ulwa $-k a$ affixation is generated in exactly two syntactic contexts: (i) on a PC root, and (ii) on the possessed noun in a possessive noun phrase. Once $-k a$ suffixation has occurred once on a root, the result is a noun, and the grammar of Ulwa does not suffix nouns with $-k a$ except when they head possessive NPs.
} 
are common. For example, it is difficult for naive speakers to conceive of the possessor and possessed in a noun phrase like the house's door or the car's wheel in (21) as standing in anything other than the part/whole relation to one another. This situation is very much parallel to the one we are dealing with here.

For now, then, we let the theory generate both readings, leaving it open whether $-k a$ watah constructions do in fact have both, and, if not, what blocks the unwanted one. The more important point here is that $-k a$ watah constructions have a straightforward meaning which our analysis derives, unlike the analysis of Koontz-Garboden and Francez (2010).

\subsection{Reanalyzing double $-k a$ constructions}

As discussed above, all nouns heading a possessive NP are marked with possessive $\mathrm{NP}-k a(30-\mathrm{a})$. The same is true of the nouns derived from roots by suffixing $-k a$ (30-b), giving rise to double $-k a$ constructions. These constructions pose a similar problem to $-k a$ watah constructions, and their semantics similarly becomes straightforward when $\pi$ is interpreted as $\preceq$ when combining with a root.

a. Alberto pan-ka

Alberto stick-3SING

'Alberto's stick'

b. bilam sikamh-ka-ka

fish stench-3SING-3SING

'the fish's stench'

(Mar06-56)

We propose that in the head noun of (30-b), sikamh-ka, $-k a$ contributes the relation $\preceq$. In this case, as was shown above, the meaning of the derived noun is equivalent to that of the bare root-both denote the substance named by the root. Thus, the noun sikamh-ka simply denotes the set of portions of stench. In combination with the possessor noun bilam 'fish', the entire possessive NP denotes the set of portions of stench that the fish bears the relation $R$ to, or in other words, the fish's stench. ${ }^{9}$ (31) shows the derivation of (30-b).

$$
\begin{array}{ll}
\text { a. } & \llbracket \text { sikamh- } \rrbracket \lambda p \cdot \operatorname{stench}(p) \\
\text { b. } & \llbracket \text { sikamh-ka } \rrbracket=\lambda q \cdot \exists p[p \preceq q \& \operatorname{stench}(p)] \\
\text { c. } & \llbracket \text { sikamh-ka-ka } \rrbracket \llbracket-\mathrm{ka} \rrbracket(\llbracket \text { sikamh-ka } \rrbracket)= \\
& \lambda P \lambda x \lambda y \cdot R(x, y) \& P(y)(\lambda q \cdot \exists p[p \preceq q \& \operatorname{stench}(p)])= \\
& \lambda x \lambda y \cdot R(x, y) \& \exists p[p \preceq y \& \operatorname{stench}(p)] \\
\text { d. } & \llbracket \text { bilam sikamh-ka-ka } \rrbracket(\llbracket \operatorname{bilam} \rrbracket) \llbracket \operatorname{sikamh}-\mathrm{ka}-\mathrm{ka} \rrbracket= \\
& \lambda x \lambda y \cdot R(x, y) \& \exists p[p \preceq y \& \operatorname{stench}(p)](\text { the-fish })= \\
& \lambda y \cdot R(\text { the-fish, } y) \& \exists p[p \preceq y \& \operatorname{stench}(p)] \\
& =\text { the set of portions of stench that the fish bears } R \text { to }
\end{array}
$$

\footnotetext{
${ }^{9}$ Here again we assume a description theory of possessives for simplicity. This is not an essential assumption, see references in fn. 3 for alternatives in which possessive NPs denote generalized quantifiers. In such an account, the noun phrase bilam sikamhkaka would denote, roughly, the set of sets that includes the fish's stench.
} 
The key step in this derivation is (31-b), in which the possessive relation contributed by $-k a$ is resolved to $\preceq$. This is what guarantees that the denotation of sikamhka is identical to the root sikamh-, allowing the denotation of the full possessive noun phrase to be, as in (31-d), the set of stench portions that the fish has. Thus, our reanalysis of the data now assigns to the sentence (13-a) above its most salient reading, namely that the fish's stench (rather than something stinky that the fish has) alerts the speaker that Bob has fish. ${ }^{10}$

As in the case of $-k a$ watah constructions, our analysis does also generate the meaning that Koontz-Garboden and Francez (2010) does. This happens when $\pi$ is resolved to $R$ rather than $\preceq$ in the combination of $-k a$ with the root. As before, we allow the system to generate this meaning, noting that it is an open question whether this meaning actually exists, how it might be diagnosed in field conditions, and what blocks it if it does not exist. The advantage of the proposed analysis, in contrast with Koontz-Garboden and Francez (2010), is that it generates the reading that we know to be attested and salient.

\section{Conclusion}

This paper discussed two constructions of Ulwa that seemed to cast doubt on the viability of the Koontz-Garboden and Francez (2010) attempt to provide a semantic explanation for the puzzling distribution of $-k a$ in Ulwa, on both property concept nouns and possessed nouns in a possessive NP. We showed that modeling the semantics for property concept roots using an ontology of substances, and cashing out the observation that possessive constructions are harnessed across languages to express part-whole relations, affords an intuitive analysis of the relevant constructions that removes the threat they pose for a semantic explanation of $-k a$. The resulting analysis not only derives correct truth conditions, but also explains the free variation between bare PC roots and derived property concept nouns in $-k a$ as complements of watah, which are treated as truth conditionally equivalent in particular circumstances. Furthermore, the facts discussed here constitute additional evidence for linking the seemingly unique Ulwa pattern to a more general grammatical phenomenon, documented by Koontz-Garboden and Francez (2010) and Francez and Koontz-Garboden (2015) across unrelated languages, namely possessive strategies of predication: the appearance of possessive morphology in constructions expressing property concept predication.

Acknowledgements We are grateful to the community of Karawala and the Ulwa Language Project, particularly Alberto Santiago, Lorinda Martínez Lacayo, Clementina Simon, Abanel Lacayo, Francisco Santiago, and Kandler Santiago for collaboration in work on Ulwa. For comments on the work reported here, we acknowledge the audience at WSCLA 2012, three thoughtful NLLT reviewers, and Louise McNally. Thanks are also due to Tom Green for making available an electronic version of the Ulwa dictionary. This work is supported financially by Arts and Humanities Research Council Grant AH/H033645/1.

\footnotetext{
${ }^{10} \mathrm{~A}$ reviewer asks whether the double $-k a$ construction is possible with nouns as well as roots. The answer is that it is not, for the syntactic reason discussed in footnote 8. $-k a$ affixation only applies to roots and to possessive nouns, and, consequently, $-k a$ stacking is only possible when a noun derived by $-k a$ affixation is the head of a possessive NP.
} 
Open Access This article is distributed under the terms of the Creative Commons Attribution 4.0 International License (http://creativecommons.org/licenses/by/4.0/), which permits unrestricted use, distribution, and reproduction in any medium, provided you give appropriate credit to the original author(s) and the source, provide a link to the Creative Commons license, and indicate if changes were made.

\section{References}

Barker, Chris. 1995. Possessive descriptions. Stanford: CSLI Publications.

Chierchia, Gennaro, and Raymond Turner. 1988. Semantics and property theory. Linguistics and Philosophy 11: 261-302.

Dixon, Robert Malcolm Ward. 1982. Where have all the adjectives gone?: And other essays in semantics and syntax. Mouton: The Hague.

Francez, Itamar. 2009. Quantification in possessives. In Semantics and Linguistic Theory (SALT) 19, Ithaca: Cornell Linguistics Circle.

Francez, Itamar, and Andrew Koontz-Garboden. 2015. Semantic variation and the grammar of property concepts. Language 91: 3.

Green, Thomas. 1992. Covert clause structure in the Miskitu noun phrase. Unpublished MIT ms. Available online at: http://www.slaxicon.org/papers/miskdp/2003-02/.

Green, Thomas. 1999. A lexicographic study of Ulwa, Doctoral Dissertation, MIT, Cambridge, MA.

Green, Thomas. 2004. Electronic version of dictionary in Green (1999). Unpublished raw XML.

Heine, Bernd. 1997. Possession: Cognitive sources, forces, and grammaticalization. Cambridge: Cambridge University Press.

Jensen, Per Anker, and Carl Vikner. 1996. The double nature of the verb have. LAMBDA 21: 25-37.

Koontz-Garboden, Andrew. 2007. States, changes of state, and the Monotonicity Hypothesis. Doctoral Dissertation, Stanford University, Stanford, CA.

Koontz-Garboden, Andrew. 2009a. Ulwa evidentials: A preliminary overview. In The structure and constituency of the languages of the Americas 13 and 14, 157-170. Vancouver: UBC Working Papers in Linguistics.

Koontz-Garboden, Andrew. 2009b. Ulwa verb class morphology. International Journal of American Linguistics 75: 453-512.

Koontz-Garboden, Andrew. 2015, in press. Thoughts on diagnosing morphomicity: A case study from Ulwa. In The morphome debate: Diagnosing and analysing morphomic patterns, eds. Ana Luís and Ricardo Bermúdez-Otero. Oxford: Oxford University Press.

Koontz-Garboden, Andrew, and Itamar Francez. 2010. Possessed properties in Ulwa. Natural Language Semantics 18: 197-240.

Link, Godehard. 2002. The logical analysis of plurals and mass terms: A lattice-theoretical approach. In Formal semantics: The essential readings, eds. Paul Portner and Barbara Partee, 127-146. Oxford: Blackwell. Originally published 1983 in Rainier Bäuerle, Christoph Schwarze, and Arn von Stechow, eds., Meaning, use, and interpretation of language, de Gruyter, Berlin, pp. 302-323.

McCarthy, John, and Alan Prince. 1998. Prosodic morphology. In Handbook of morphology, eds. Arnold Zwicky and Andrew Spencer, 283-305. Oxford: Blackwell.

Partee, Barbara. 1997. Genitives-a case study. In Handbook of logic and language, eds. Johan van Benthem and Alice ter Meulen, 464-470. Amsterdam: Elsevier.

Peters, Stanley, and Dag Westerståhl. 2006. Quantifiers in language and logic. Oxford: Oxford University Press.

Sassoon, Galit. 2013. A typology of multidimensional adjectives. Journal of Semantics 30: 335-380.

Tham, Shiao Wei. 2006. The definiteness effect in English have sentences. In 2004 Texas Linguistics Society Conference, 137-149. Somerville: Cascadilla Proceedings Project.

Vikner, Carl, and Per Anker Jensen. 2002. A semantic analysis of the English genitive. Interaction of lexical and formal semantics. Studia Linguistica 56: 191-226. 